Peer-Reviewed Article

ISSN: 2162-3104 Print/ ISSN: 2166-3750 Online

Volume 6, Issue 1 (2016), pp. 73-92

(C) Journal of International Students

http://jistudents.org/

\title{
Explaining the Effectiveness of the Contrast Culture Method for Managing Interpersonal Interactions Across Cultures
}

\author{
Hiroyoshi Hiratsuka \\ Aoyama Gakuin University (Japan) \\ Hanako Suzuki \\ University of Tsukuba (Japan) \\ Alexis Pusina \\ Independent English Teacher (China)
}

\begin{abstract}
One of the current challenges in the field of intercultural education comes from the limited availability of training efficacy studies. The present study focused on explaining the effectiveness of the Contrast Culture Method (CCM) as an intercultural education method for managing interpersonal interactions across cultures between graduate international students and their local counterparts in an academic program in Japan. By incorporating a qualitative methodology through the grounded theory, the study explained a context of domestic interpersonal relations across cultures in Japan. The result showed CCM's effectiveness based on respondents' reflective accounts, and supported the ideas suggested by the original study. The article concludes with future directions for research and application of CCM.
\end{abstract}

Keywords: Contrast Culture Method, Training Evaluation, Intercultural Education

Student diversity brings rare educational benefits for personal growth while it challenges the individuals in a variety of interpersonal obstacles in different academic contexts. As Japan is considered one of the emerging destinations of degree-seeking international students (Verbik \& Lasanowski, 
2007), and the number has been steadily increasing in the last decade (JASSO, 2010), the trend of global student mobility confronts many Japanese universities with educational challenges for managing student diversity. The researchers have been working on issues of these international students within the academic contexts, and have been collaborating together to develop effective ways of assisting their international students with managing transitional stress to Japanese culture.

A variety of issues related to international students' transition into the new culture exists, and the researchers' professional experience has informed the international students' needs in the new culture in five different levels based on the available literature: interpersonal level (Stewart, 1995), intragroup level (Halverson \& Tirmizi, 2008), intergroup level (Berry, 2004), organizational/institutional level (Scott, 2001), and community level (Rutherford, 1990). The researchers explored a conceptual framework in the existing body of literature, and arrived at Stewart's (1995) theory of culture which informed researchers' professional practice. Stewart argued culture is "an organization of diversity and not of uniformity" (1995, p. 56), and described it as a “...'control mechanisms' that organizes human diversity and govern behaviors” (1987, p. 147). Stewart's theory also informed the researchers as a theoretical framework for this study since culture organizes diversity of individual thought, attitudes, and behaviors. Organizational differences of the individual mind at the interpersonal level can become either a source of cooperative creativity or relational conflicts (Stewart, 1995).

The researchers were most concerned with providing assistance for improving international students' interpersonal communication because when international students transition into the new culture, they face challenges when interacting with the host members. A lack of proficiency in a local language and differences between students' own culture and the local culture are often mentioned as two major obstacles among the international students (Marginson, Nyland, Erlenawati, \& Forbes-Mewett, 2010; Ward, Bochner, \& Furnham, 2001), and this is also true of international students in Japanese universities (JASSO, 2008; Tohoku University, 2008). In a case of host Japanese students at Ritsumeikan Asia Pacific University (APU), which enrolls a high percentage of international students in the student population (roughly $40 \%$ ), local students indicated intercultural understanding as one of their needs during university orientations (Miyahara, Ito, Taninaka, \& Murata, 2009). Sometimes international students' lack of familiarity with the organization of interpersonal interactions in Japanese culture leads to misunderstanding of the Japanese people but also relational conflicts with them. As a result, the international students in Japanese universities often encounter a variety of 
academic and social relational challenges such as the faculty-student advising sessions and joining the extra-curricular activity/club groups in Japan (Hiratsuka, 2012).

Especially for international students without past overseas relocation experience, the transitional process from their home culture to their destination culture puts a tremendous burden on them in the form of transition shock (Bennett, 1998) during the cultural survival phase (Stewart, 1986). Furthermore, university administrators are often unfamiliar or unable to provide transitional assistance preparation as a form of intercultural educational activities for the university students (Hoff \& Kappler, 2005). Therefore, the international students often become responsible for making their transition on their own (Ward et al., 2001). A lack of support for reducing transitional stress can increase a variety of risks for international students' academic success.

The international students often face challenges interacting with their instructors, staff members, and local students. Providing learning assistance may contribute to overcome these challenges in interpersonal interactions across cultures, and happens to be an important educational aspect of international student services. The successful management of interpersonal interactions across cultures depends on applying various intercultural strategies of acculturation as well as intergroup relations between new comers and host members (Berry, 2003, 2004). Throughout their academic durations, these international students also are faced with new learning, coping with stress, and shaping their identities (Ward, 2004) through the new cultural contacts. One of the most common responses to reduce international students' burden and soften their transitional stress is offering orientations after arrival to the destination (Gudykunst, 2004; Grove \& Torbiorn, 1993; Martin, 1994; Torbiorn, 1994; Ward, 2004).

Among available educational approaches, the Contrast Culture Method was originally developed to prepare the US military personnel on overseas missions, and intended to help with overcoming cultural differences through the interpersonal interactions under complex situations abroad. A research team led by Stewart at HumPRO at George Washington University conducted an assessment study of the White Star Teams that operated in Laos, and they reviewed existing instructional materials for overseas assignments at the time. A lack of satisfactory resources for military and civilian personnel preparation for their overseas missions led the research team to construct a new concept and a training strategy, Contrast Culture Method (Stewart, 1995; Wasilewski \& Kawakami, 2012). However, its effectiveness has not been evaluated experimentally due to a lack of appropriate assessment instrument availability since the time of its formulation (Kimmel, 1995; Stewart, 1966). The existing proof in the 
original study does not meet the social scientific rigor and standard as an experimental design, and included a number of limitations. There are only few qualitative studies to illustrate the Method's effects (Fujimoto, 2004; Fujimoto, 2010; Hiratsuka \& Fujimoto, 2012). The CCM's causality and contribution to managing interpersonal interaction across cultures remain in question. An investigative opportunity exists for the CCM researchers and practitioners to explore the Method's effectiveness within academic contexts as more and more Japanese universities encounter issues of managing student diversity. Therefore, there is a need for continuing research about the effectiveness of Contrast Culture Method as a training strategy to manage interpersonal relations across cultures within the Japanese university context.

The study asked the following questions to guide inquiry:

1. In what ways do international students take advantage of their learning from CCM to manage their interpersonal relations with members of a Japanese university?

2. How do the participants recognize CCM as a useful and beneficial educational activity?

3. How do the participants apply different learning gains to improve their interpersonal interactions across cultures in academic contexts?

\section{THEORETICAL FOUNDATION}

Illustrating the trainee's reference culture objectively necessitated a trained actor based on a neutral and non-specific culture to simulate interpersonal interactions in realistic real-life contexts. A generic culture to reflect a contrasting image of the trainee's own culture became the core construct of CCM. The method constructed three main concepts to make the method operational: Reference Culture, Contrast Culture, and Cultural Differences. In a theatrical format, the interpersonal interactions between two role players of the reference culture and contrast culture convey the existence of cultural differences (Stewart, 1966, 1984, 1995; Stewart, Danielian, \& Foster, 1969; Wasilewski \& Kawakami, 2012).

When the trainees are US Americans, then the reference culture focuses on the US American culture which reflects a summary of particular thoughts, attitudes, and behaviors based on US American values and assumptions. A trained actor portrays a culture contrasting with the trainee's US American culture. Contrast culture actor's main function focuses on being a medium for raising awareness of the trainee's reference culture or cultural self-awareness (Stewart, 1966, 1984, 1995; Stewart, Danielian, \& Foster, 1969; Wasilewski \& Kawakami, 2012). Overcoming cultural differences requires applying a variety of intercultural strategies to improve 
interactions between the members of cultural groups (Berry, 2003, 2004). Once the trainee became aware of his/her own culture by simulating the interpersonal interactions across cultures in a realistic context, he or she would therefore be able to refrain from applying thoughts and behaviors based on his/or own cultures as a result of CCM. Eventually, the trainee would become open to learn and to utilize different intercultural strategies with people from the target culture.

\section{Table 1. Summary of Contrast Culture Method Concepts}

\begin{tabular}{ll}
\hline Concept & Definition \\
\hline $\begin{array}{l}\text { Reference } \\
\text { Culture }\end{array}$ & $\begin{array}{l}\text { It refers to the culture with which the } \\
\text { trainee is most closely associated. } \\
\text { Contrast }\end{array}$ \\
$\begin{array}{l}\text { It provides a mirror image of the trainee's } \\
\text { reference culture by illuminating its } \\
\text { underpinning thoughts, values, attitudes, } \\
\text { and behaviors. } \\
\text { It refers to the culture of an individual with } \\
\text { which the trainee works professionally. }\end{array}$ \\
$\begin{array}{l}\text { It means the organizational differences of } \\
\text { Differences }\end{array}$ \\
$\begin{array}{l}\text { thoughts, values, attitudes, and behaviors } \\
\text { between two individuals at the levels of } \\
\text { interpersonal Relations. }\end{array}$
\end{tabular}

The experience of one's own culture including one's assumptions, ethnocentrism, and stereotypes, tends to be unconscious, natural, and normal (Stewart, 1995), and raising objective awareness of one's own culture "...results in greater understanding and empathy with the values and assumptions of another culture” (Stewart, et.al., 1969, p.8). Bhawuk and Brislin, however, criticized CCM's weakness as not necessarily contributing to a participant's learning about any specific cultures and his/her target culture (2000). To overcome this shortcoming, Kimmel (1995) suggested integrating CCM into a larger program, and including culture-specific lessons to explain a target or local culture with which a trainee is going to interact.

Improving the quality of interpersonal relations across cultures should focus on learning about one's own culture first (Stewart, 1984, 1995; Stewart et.al., 1969), and learning about oneself and one's own culture is the foundation of the Contrast Culture concept. Therefore, the training strategy focused on generating participants' "...insight into how their own culture is 
perceived by others and how its assumptions and strategies contribute to or detract from cultural interactions" (Stewart, 1995, p. 56). CCM contextualizes a situation for the individuals to engage in simulated experiences that are emotionally and intellectually stimulating by challenging their own assumptions and values.

\section{Past Case Applications, Summative Reviews, and Criticism}

As Stewart argued (1995), Contrast Culture Method can be applied to different trainees by formulating the training design based on the reference culture of the target audience, and the method has been recognized in the defense industry (Kimmel, 1995), business (Folwer \& Blohm, 2004; Wasilewski \& Kawakami, 2012), and higher education (La Brack, 1993; Pusch, 2004; Reki, 2008; Weaver, 1993), primarily in the U.S. More recently, special interest group members have been practicing CCM in Japan since the 1990s (Wasilewski \& Kawakami, 2012) targeting the Japanese university domestic and international students, staff members, and instructors (Fujimoto, 2004, 2010; Hiratsuka \& Fujimoto, 2012). Kume (2001) also designed an instructional video based on CCM by modifying the method for the Japanese university students, and Kume described positive responses from the audience in his study. While these cases showed applicability and flexibility of the training strategy to a variety of target audiences and different sectors, these articles do not include a systematic evaluation component of CCM's effectiveness.

A lack of empirical evidence continues to allow questions to be raised regarding CCM's effectiveness and its benefits. Only one experimental result in the original study supports CCM's effectiveness as a training method (Kimmel, 1995; Stewart, et al., 1969). Stewart et al. (1969) also concluded that the method improved cultural self-awareness as one of the training outcomes. A qualitative study by Hiratsuka and Fujimoto (2012) concluded that developing an ability to observe one's reactions and behaviors was one of CCM's several observed outcomes through face-toface interviews. In addition, the existing summative review of studies concluded that CCM is valuable and favorable to the trainees (See Table 1).

Among a variety of issues in the field of intercultural education and training, two interrelated issues on training evaluation pose a question (Kealey \& Protheore, 1996; Landis \& Wasilewski, 1999) on evaluating training effectiveness. One of the major criticisms includes a need for developing and utilizing a reliable instrument in evaluative studies (Landis \& Wasilewski, 1999; Mendenhall et al., 2004; Timmy-Toomy, 2004). Stewart (1966) and Stewart et al. (1969) also recognized that the existing data in the original study would require developing an appropriate instrument. Only recently have there been a variety of more reliable 
instruments available to measure training effectiveness in the field (Bhawuk \& Brislin, 2000; Paige, 2004: Paige \& Stallman, 2007) to potentially correct this criticism.

\section{Table 2. Evaluation Studies included Contrast Culture Method}

\begin{tabular}{ll}
\hline \multicolumn{1}{c}{ Available Studies } & \multicolumn{1}{c}{ Evaluation Results } \\
\hline Bhawuk and Brislin & Valuable. \\
$\begin{array}{l}\text { Fowler and Blohm } \\
(2004)\end{array}$ & High impact value. \\
Kimmel (1995) & Valuable. \\
Pusch (2004) & The gold standard in the field. \\
Stewart (1966) & Trainee's responses to be favorable. \\
\hline
\end{tabular}

Another criticism of field's approaches consists of a need for improving the methodological rigor in order to evaluate efficacy based on the traditional social scientific methodological assumptions and orientations (Kealey \& Protheroe, 1996; Landis \& Wasilewski, 1999; Mendenhall et al., 2004). Stewart (1966) also identified that the original study lacked scientific rigor due to a small sample size. Two recommendations exists to correct this criticism: designing domestically-focused training approaches to analyze intercultural effectiveness to avoid difficulty for controlling variables (Kealey \& Protheroe, 1996) and including qualitative studies to explain the context of empirical measurement (Mendenhall et al., 2004).

Contrast Culture Method remains to be one of the most valuable and favorable approaches in the intercultural education field. Better evaluative studies to explain and prove effectiveness of training and education approaches are needed in the field as a whole, and there is a need for contributing to this gap in the literature. While other researchers would continue to assist the current field need by employing quantitative methods, this study follows the design suggestions to incorporate a qualitative study to explain the context (Mendenhall et al., 2004) of domestic interpersonal interactions across cultures (Kealey \& Protheore, 1996).

\section{METHOD}

This research project was designed as a qualitative study, and employed the grounded theory approach to conceptualize themes from the data by using a focus group as a collection method. The researchers selected the focus group for its methodological uniqueness and because of resource limitations. The study also utilized the grounded theory approach as an analytical 
strategy (Creswell, 2009; Strauss \& Corbin, 1990), and focused on drawing themes and classifications based on the participants' descriptive data in the audio transcription and video footage. The process included organizing and analyzing the data to identify common themes, patterns, categories, and relationships between in order to establish new meanings and make qualitative generalization to a broader theory (Creswell, 2009; Strauss \& Corbin, 1990).

\section{Researchers' Role}

The research project took a team approach to keep individual biases and assumptions checked through constant questioning and giving feedback, and the researchers' demographic representations (nationality, age group, gender, educational history) allowed the team to diversify their values to bring strength to the research design. All the researchers have residential experience in both the US and Japan through their post-graduate education and profession. The first researcher is a faculty administrator of a graduate education program, and has been researching, teaching and advising international students in the U.S., Japan, and Germany. The second researcher is a faculty member specialized in counseling psychology, and has been providing preventative intervention, consultation, and counseling for international students in Japanese universities. The third researcher has been an English teacher at Japanese universities and high schools specialized in intercultural communication.

Prior to the data collection and analysis phases, the researchers agreed on the position that an individual is unique, and everyone is different from one other in this study. Every international student experiences interpersonal interactions differently, and his or her individual experience forms thoughts, attitudes, and behaviors that are unique to the individuals. The researchers recognized that interpersonal interactions across cultures are individually dynamic, and involve complex personal frustration, adjustments, unexpected surprises, and transitions within a new environment. The study's challenge was to focus on finding common themes in such diverse encounters within individually unique complexity and dynamic experience.

\section{Methodological Validity and Ethical Conducts}

The university where the lead researcher is affiliated did not have an organizational unit which functions as university's Institutional Review Board for approval, but the study has been supervised under the program executive committee which is responsible for evaluating study's ethical concerns. Under the committee's review, the researchers ensured ethical conduct in this research project by providing and receiving signatures on 
study's informed consent form from the participants in addition to having an expert on the team to ensure the ethical conduct of the researchers before the data collection phase. The researchers also maintained to the best of their ability to maintain methodological validity (Strauss \& Corbin, 1990), and employed a series of validity strategies to ensure the methodological standard in qualitatively oriented studies: data triangulation by visual and sound data collection, a research project protocol design and database management, interview protocol design, peer debriefing by an external member, intercorder agreement prior to the study by designing a codebook, and cross-checking during the analysis phase (Creswell, 2009).

\section{Participants and Contexts}

The participants were international students enrolled at a Japanese university who had been studying in Japan for one year under a governmental scholarship program. They all share the same profession and hold leadership positions in their respective public administrations. There are eight students in the program. The demographic backgrounds of the program participants reflected a high level of group diversity. These participants came from eight different countries, and six different languages were spoken in addition to English as the instructional language and personal communication in the program. These students were in different stages of their careers, and their ages ranged from mid-20s to mid-40s. These students also practiced three different religions: Christianity, Islam, and Buddhism. In addition, some students had prior overseas experience professionally or educationally while other students had left their home countries for the first time in their lives to participate in a degree program overseas. These descriptions illustrate the participants' complex and dynamic experience based on their group's high level of diversity. Within this group, six students participated in the CCM session in their cocurricular activities.

\section{Procedure}

The study's procedure involved the following components: treatment (CCM implementation), focus group protocol design, data collection, and data analysis and interpretation.

Treatment. The participants received Contrast Culture Method (CCM) as a part of Intercultural Education Program (IEP) to assist their transition into the Japanese culture in the 2012 fall term at the participants' university. The CCM session lasted for roughly three hours, and included a scenario which represented a generic story of interpersonal interactions between a faculty member and a student. Once the role-play was 
completed, the facilitator interviewed the role players, and the participants were also given opportunities to interview the role-players.

Focus group protocol design. Qualitative research projects involve the researchers' consistent interactions with informants as a part of an important methodological approach, and the researchers believed that, correctly done, the focus group would bring the participants' active and interactive discussion to generate rich data (Kirk \& Miller, 1986; O’Leary, 2005). Prior to the study, the researchers developed an interview protocol for the focus group approach, and formulated a series of semi-structured questions for the facilitators. The interview questions included:

- How did the group feel leading up to the workshop?

- What word can you use to define how you felt during the workshop?

- How did you feel after the role-play discussion?

- How did the CCM workshop/training affect your interactions with other people?

- Did the CCM workshop/training in any way lead/allow you to experience a deeper or more profound understanding of your own culture?

In the interview questions, the CCM session was referred to as a workshop, and was reflected on during the focus group session. In addition, the focus group design involved two facilitators. The first facilitator was assigned to provide a series of questions in order to elicit participants' responses. The second facilitator was assigned to take notes and observe the participants in addition to operating a video camera and an audio recorder to document the data during the session.

Data collection. The focus group was conducted in English, and lasted approximately two hours. The data was recorded by a video camera and a digital recorder for the purpose of triangulation. Before collecting data, the researchers asked the participants for their permissions to collect data, and explained their roles in the study. The consent form explained researchers' intention to maintain data's confidentiality at the highest professional manner, and affirmed their volunteer roles.

Data analysis and interpretation. The data analysis session included three separate phases. First, one of the researchers transcribed the audio data for analysis. Second, the researchers met to generate the original codebook for data analysis based on the literature review (See Table 2), and the checked the codebook during the open coding phase. After the review and discussion, the researchers fine-tuned the codebook through the axial 
coding phase. Finally, the research team analyzed the video footage against the transcribed data in order to verify the result to generate themes against the codebook in the selective coding phase. During the final phase, the researchers cross-checked the data with one other by having analyzed the video footage and transcribed data to maintain qualitative reliability (Creswell, 2009).

\section{Table 3. Study's Analytical Codebook}

\begin{tabular}{|c|c|}
\hline Code & Theme \\
\hline Theme 1. Reflective & Comments and indications related to \\
\hline Description on Local/Target & participant's view on culture other than \\
\hline Culture & his/her own. \\
\hline Theme 2. Reflective & Comments and indications related to \\
\hline Description on One's Own & participant’s view on his/her own \\
\hline Culture & cultures. \\
\hline Theme 3. Reflective & Comments and indications related to \\
\hline Description on Cultural & participant's view on differences in \\
\hline Differences & $\begin{array}{l}\text { intercultural strategies between his/her } \\
\text { culture and another culture. }\end{array}$ \\
\hline Theme 4. Reflective & Comments and indications related to \\
\hline Description on CCM's Values & CCM’s values and benefits from \\
\hline and Benefits from & participant’s views. \\
\hline Participants’ Views & \\
\hline
\end{tabular}

\section{RESULTS}

From these descriptive accounts, the researchers analyzed data to formulate two major themes: 1) Participants' recognition of CCM's three core concepts of culture (local/target culture, reference culture, and cultural differences) at the interpersonal level, 2) CCM's values and benefits for improving interpersonal interactions across cultures. Table 3 illustrated the researchers' analysis based on the data from the participants' responses.

\section{CCM's Three Core Concepts of Culture at the Interpersonal Level}

The participants described CCM's core concepts of culture by referring to their interpersonal interaction experiences in the Japanese academic context, and illustrated the evidence of CCM's core concepts of culture in their accounts: local/target culture, one's own culture, and cultural differences (Stewart, 1966; 1995; Stewart et al., 1969). For example, P6 described, “...The mindset of people here is different...” to illustrate this 
Table 4. Selected Descriptions for Study's Major Themes

\begin{tabular}{|c|c|}
\hline Major Themes & Participant (P)'s Responses \\
\hline $\begin{array}{l}\text { Theme 1: } \\
\text { Local/Target } \\
\text { Culture }\end{array}$ & $\begin{array}{l}\text {...This is how things are done here... (P1) } \\
\text {...to understand about Japanese culture... (P1) } \\
\text {...Angry ...because I discovered that I 100\% do not agree } \\
\text { with my advisor...(P3) } \\
\text { “...The mindset of people here is different...”(P6) }\end{array}$ \\
\hline $\begin{array}{l}\text { Theme 2: One's } \\
\text { Own Cultures }\end{array}$ & $\begin{array}{l}\text { “...made me realize some things I usually give (take) for } \\
\text { granted about my own culture...” (P1) } \\
\text {...I am coming from a culture very similar to Japanese } \\
\text {...pursuing harmony ...if a professor has a line, I would } \\
\text { not cross or push... (P2) } \\
\text {...I associated more with the student, but I am not as } \\
\text { aggressive... (P4) }\end{array}$ \\
\hline $\begin{array}{l}\text { Theme 3: } \\
\text { Cultural } \\
\text { Differences }\end{array}$ & $\begin{array}{l}\text {...instead, working together more and improve the } \\
\text { harmony... (P1) } \\
\text {...So we should adopt... (P1) } \\
\text {...I will accept the style [of professor]... (P2) } \\
\text {...I feel in the middle, that my professor helped me but at } \\
\text { the same time I have to rely on my own... (P2) } \\
\text {...getting out of comfort zone... (P3) } \\
\text {...This is not a problem of expectation, but a problem of } \\
\text { communication... (P4) }\end{array}$ \\
\hline $\begin{array}{l}\text { Theme 4: } \\
\text { CCM's Values } \\
\text { and Benefits } \\
\text { from } \\
\text { Participants' } \\
\text { Views }\end{array}$ & $\begin{array}{l}\text {...helped us realize that it is always not the same the way } \\
\text { we expect or want... (P1) } \\
\text {...confident how to deal with advisor... (P1) } \\
\text {...The workshop made me more aware of relationships } \\
\text { with the advisor... (P2) } \\
\text {...benefited a relationship with my advisors... (P2) } \\
\text {...helped improve relationships with an advisor... (P3) } \\
\text {...open our eyes... (P3) } \\
\text {...helped me a lot, at the time I had difficulties getting } \\
\text { replies from the professor... (P4) } \\
\text {... became more confident... (P4) } \\
\text {...motivated to work harder... (P5) } \\
\text {...The workshop helped me to realize the role of } \\
\text { advisors... (P5) }\end{array}$ \\
\hline
\end{tabular}


participant's recognition of another culture, theme one in the table. P1 also explained, CCM “....made me realize some things I usually give [take] for granted about my own culture...” by recognizing the participant's referral to his/her own culture as a description of the theme two (reference culture). In addition, P4 said, "[the relationship issues with the advisor] is not a problem of expectation, but a problem of communication..." to identify the source of a problem as communication style differences in interpersonal relations across cultures. P4's description reflected the theme three (cultural differences). These descriptive accounts symbolized as illustrations of the participants' recognition of CCM's core concepts of culture at the interpersonal level, and reflected CCM's theoretical foundation (Stewart, 1966, 1995; Stewart et al., 1969).

\section{CCM's Values and Benefits for Improving Interpersonal Interactions Across Cultures}

The participants' reflective accounts ensured CCM's values and benefits for contributing to improving their faculty-student relations in the Japanese academic context. In theme four in the table, some participants explained that CCM helped (P4) or improved (P3, P5) their interpersonal interactions with the faculty members while others commented that CCM made them aware (P2) or realize (P1) the unclear roles of the faculty members in their university. Furthermore, CCM specifically contributed to improve their confidence (P1, P4), motivation (P5), or simply opened one's eyes (P3). One person thought to work with the faculty member more collaboratively (P1). CCM confronted the participants' reference culture and values and assumptions, and assisted them to gain objective views on their own cultures as intended in the original study (Stewart, 1966, 1995; Stewart et al., 1969).

At the same time, not all participants' accounts resulted in expected remarks. They did not necessarily recognize CCM's values and benefits, and some participants expressed little or limited values and benefits from the training strategy. P4 explained, “...I feel that in this situation, my culture is much better...” This participant's expression cast value judgments instead of his objective view on the participant's own culture. Also, another participant, P6, simply responded by saying, “...No...”, and this participant did not think anything changed as a result of CCM. These accounts showed some evidence that CCM might not have contributed to achieving the method's intended outcomes for everyone due to a variety of factors. Stewart $(1966,1995)$ warranted that not all participants would respond to CCM favorably, and sometimes would not achieve CCM's desired outcomes. The result would be possibly due to the participants' lack of understanding about CCM and/or about trainee's readiness due to important 
personal and social factors in the interpersonal relations. One possible explanation could include trainee's lack of readiness for challenging his or her own assumptions and attitudes toward individuals from other cultures.

Besides Stewart's recognition on such limitations (1966, 1995), their training readiness also depends on the individual differences in the acculturation strategy framework which involve the four different strategy application (Integration, Assimilation, Separation, and Marginalization) in individual's interactions with others in a new culture (Berry, 2003, 2004). Differences in individual transitional processes also can challenge the participants' transitional outcomes in new learning, coping with new stresses, and shaping their new identities (Ward, 2004) in the target culture. Participants' individual differences in these various transitional stages may have also influenced their accounts. The participants' training readiness to confront themselves has to be considered by the facilitators as some participants might have greater challenges depending on different stages of acculturation and cultural transition.

\section{DISCUSSION}

The study originally focused on capturing the participants' reflective descriptions of interpersonal interactions across cultures in both academic and socio-cultural contexts. The study involved six participants who received CCM as a part of their co-curricular activities during their studies in Japan. While the study ensured all possible strategies to make sure study's methodological validity (Creswell, 2009; Strauss \& Corbin, 1990), the researchers recognized the small sample size as one of several main limitations in the study. At the same time, participants' responses revealed CCM challenged their values and assumptions about their interpersonal relations by creating cognitive discomfort through the role-play in order to objectively recognize culture's different categories indicated by Stewart (1966) and Stewart, et al (1969). What surprised the researchers during the analysis is that the participants' expressions focused specifically on their faculty-student interactions. Their responses regarding their daily-life issues remained salient in the data, and their issues related to faculty-student relationships became prevalent. The researchers did not expect to witness such finding in the data, and the finding resulted in some considerations for the future training design and research planning.

Since the participants' expressions illustrated their real-life settings and feelings into the role-players, such portrayals symbolized participants' underlying assumptions of the faculty role-player to be their portrayal of a Japanese faculty and the student role-player to be their portrayal of an international student. In the simulation, the two role-players should illustrate 
non-specific and neutral portrayal of interpersonal interactions across cultures; however, the participants consciously or unconsciously assigned real-life roles to the role-players. The result indicated possible occurrence of transference (Etchegoyen, 2005).

This result poses a question regarding a possible indication of contributing to their stereotypes about the target culture instead of an objective view of it. Kume (2001) also identified the same concern in his study, and the researchers suspected that this outcome resulted potentially from the role-player assignments. In the review of this group's CCM design, a seemingly Japanese actor of an older age played the advisor role, and a seemingly non-Japanese actor of a younger age played the student role.

The CCM's role-play design strongly framed the participants' contexts of interpersonal interaction across cultures, the design must articulately reflect 1 ) participants' authentic reality through careful needs assessment and 2) must assign a role-player from a culture other than the local culture (Japanese culture) for the international students in Japanese universities to avoid pushing the students toward casting their stereotypes onto the role-players should it be possible. The trainers must take the effects of the role-players' identity and role-play's contexts into greater consideration as the participants can mistakenly and/or unconsciously project their real-life situations onto the role-players.

\section{CONCLUSIONS}

The purpose of this study focused on explaining CCM's effectiveness on managing interpersonal interactions in the Japanese academic contexts. The study aimed at investigating the training strategy's theories and hypothesis developed by the original study (Stewart, 1966, 1995; Stewart et al., 1969), and applied to the international students' interpersonal interactions at a Japanese university. A culture as an organization of diversity proposed by Stewart $(1986,1995)$ at the level of interpersonal interactions guided the study, and reviewing the existing studies and criticism related to CCM and the field of intercultural education identified possible research directions and shortcomings. The study employed a grounded theory approach as a methodological choice to explain CCM's effectiveness in a particular context by utilizing focus group as a data collection strategy (Cresswell, 2009; Corbin and Strauss, 1990). The results explained CCM's core concepts of culture and values and benefits described in the original study (Stewart, 1966, 1995; Stewart, et al., 1969). Although this was an exploratory study with some limitations, the results contributed to affirming CCM's theory as well as its values and benefits by the most participants. 
CCM continues to present research and educational potentials for the future, and this study raised important questions as well as applicability to assist the international students in Japan. By focusing on analysis of domestic interpersonal interactions across culture by adding to qualitative data, the present study contributed to 1) explaining the CCM's effectiveness in a Japanese academic context, 2) building CCM's reference, 3) filling an existing gap of literature on research in the field of Intercultural Education.

The limitations continue to exist to prove the CCM's efficacy, and a lack of experimental results causes a weak legitimacy of CCM as a training strategy for improving interpersonal interactions across cultures. The CCM scholars and practitioners need to prove the method's efficacy by designing social scientifically rigorous experiments since no experimental study has attempted to replicate the expected result in the original study (Kimmel, 1995; Stewart, 2012, personal communication). Although numerically measuring the effectiveness of interpersonal interaction across cultures remains controversial, the currently available instruments in the discipline would allow researchers to design a systematic, longitudinal, evaluative study to fill the current knowledge gap.

\section{REFERENCES}

Bennett, J. (1998). Transition Shock: Putting a culture shock in perspective.

In M. J. Bennett (Ed.). Basic concepts of intercultural communication: Selected readings (pp. 215-224). Yarmouth, ME: Intercultural Press.

Berry, J. W. (2003). Conceptual approaches to acculturation. In K.M. Chun, P.B. Organista, \& G. Martin. (Eds.). Acculturation: advances in theory, measurement, and applied research (pp.17-37). Washington, DC: American Psychological Association.

Berry, J. W. (2004). Fundamental psychological processes in intercultural relations. In D. Landis, J.M. Bennett, \& M.J. Bennett (Eds.). Handbook of intercultural training (3rd ed., pp.166-184). Thousand Oaks, CA: Sage Publications, Inc.

Bhawuk, D., \& Brislin, R. W. (2000). Cross-cultural training: A review. Applied Psychology, 49(1), 162-191. doi:10.1111/1464-0597.00009

Creswell, J. W. (2009). Research design: Qualitative, quantitative, and mixed methods approaches ( $3^{\text {rd }}$ ed.). Thousand Oaks, CA: Sage Publications, Inc.

Etchegoyen, R. H. (2005). The fundamentals of psychoanalytic technique.

London: Karnac Books. Retrieved from

http://site.ebrary.com/id/10464039

Fowler, S. M., \& Blohm, J. M. (2004). An analysis of methods for 
intercultural training. In D. Landis, J.M. Bennett, \& M.J. Bennett (Eds.). Handbook of intercultural training (3rd ed., pp.37-84). Thousand Oaks, CA: Sage Publications, Inc.

Fujimoto, D. (2004). Adapting the Contrast Culture Method to the classroom. Journal of Intercultural Communication. 7, 43-61.

Fujimoto, D. (2010, October). The contrast culture method examines a teacher-student conference. JALT the LLL SIG Newsletter.

Grove, C. \& Torbiorn, I. (1993). A new conceptualization of intercultural adjustment and the goals of training. In R.M. Paige (Ed.). Education for intercultural experience (pp. 73-108). Yarmouth, ME: Intercultural Press, Inc.

Gudykunst (2004). An anxiety/uncertainty management (AUM) theory of strangers' intercultural adjustment. In Gudykunst, W.B. (Ed.). Theorizing about intercultural communication (pp. 419-457). Thousand Oaks, CA: Sage Publications, Inc.

Hall, E.T. (1984). Silent Language. New York, NY: Anchor Books. Halverson, C. B., \& Tirmizi, S. A. (2008). Effective Multicultural Teams: Theory and Practice. New York, NY: Springer.

Hinkelman, D. W. (1995). Intercultural simulation games for management education in Japan. Economic Journal of Hokkaido University, 24, 59-89.

Hiratsuka, H. (2013). The Annual Evaluation Report on Strategic Management and Intellectual Property Rights (SMIPRP) Program (2012) at Aoyama Gakuin University (AGU). Unpublished Evaluation Report. Tokyo, Japan: Aoyama Gakuin University.

Hiratsuka, H. \& Fujimoto, D. (2012). A training evaluation of the Contrast Culture Method for international graduate students in Japan. Journal of Intercultural Communication. 15. 93-108.

Hoff, J. G., \& Kappler (2005). Integrating intercultural training into education abroad programming. In J. L. Brockington, \& W. W. Hoffa, and P. C. Martin (Eds.). NAFSA's Guide to education abroad for advisors and administrators ( $3^{\text {rd }}$ ed., pp. 193-206). Washington DC: NAFSA: Association of International Educators.

Japan Student Services Organization (JASSO). (2008). Heisei 21 nendo shihiryugakusei seikatsujittai chousa. Retrieved from http://www.jasso.go.jp/scholarship/documents/ryujchosa21p04.pdf Japan Student Services Organization (JASSO). International students in Japan 2010 (2010, December 22). Retrieved from http://www.jasso.go.jp/statistics/intl_student/data10_e.html

Kealey, D.J., \& Protheroe, D.R. (1996). The effectiveness of cross-cultural training for expatriates: An assessment of the literature on the issue. International Journal of Intercultural Relations, 20(2), 141-165. 
Kimmel, P. R. (1995). Facilitating the Contrast-Culture Method. In S. $M$. Fowler \& M. G. Mumford (Eds.). Intercultural sourcebook: Crosscultural training methods. Vol.1. (pp. 69-80). Yarmouth, ME: Intercultural Press, Inc.

Kirk, J. \& Miller, M. L. (1986). Reliability and validity in qualitative research. Thousand Oaks, CA: Sage Publications, Inc.

Kume, T. (2001). Educational video development for intercultural communication and its effects: Centering on the contrast-culture method. Intercultural Communication Studies, 12, 113-130.

Landis, D., \& Wasilewski, J. H. (1999). Reflections on 22 years of the International Journal of Intercultural Relations and 23 years in other areas of intercultural practice. International Journal of Intercultural Relations, 23(4), 535-574. doi:10.1016/S01471767(99)00009-7

La Brack, B. (1993). The missing linkage: the process of integrating orientation and reentry. In R.M.Paige (Ed.). Education for intercultural experience ( ${ }^{\text {nd }}$ Ed., pp. 241-280). Yarmouth, NE: Intercultural Press, Inc.

Marginson, S., Nyland, C., Erlenawati, S., \& Forbes-Mewett, H. (Eds.) (2010). International student security. Cambridge, UK: Cambridge University Press.

Martin, J. (1994). Intercultural communication: A unifying concept for international education exchange. In G. Althen (Ed.). Learning across cultures (pp. 9-29). Washington D.C.: NAFSA, Association of International Educators.

Miyahara, K., Ito, N., Taninaka, A., \& Murata, Y. (2009). Creation of a "Reassure" style orientation program with student participation. University Administration Studies, 4, 65-78.

Mendenhall, M.E., Ehnert, I., Kuhlmann, T.M., Oddou, G., Osland, J. S., \& Stahl, G.K. (2004). Evaluation studies of cross-cultural training programs: A review of literature from 1988-2000. In D. Landis, J.M. Bennett, \& M.J. Bennett (Eds.). Handbook of intercultural training (3rd ed., pp. 129-144). Thousand Oaks, CA: Sage Publications, Inc.

O’Leary, Z. (2005). Researching real-world problems: A guide to methods of inquiry. Thousand Oak, CA: Sage, Publications, Inc.

Paige, R. M. (2004). Instrumentation in intercultural training. In D. Landis, J.M. Bennett, \& M.J. Bennett (Eds.). Handbook of intercultural training (3rd ed., pp. 85-128). Thousand Oaks, CA: Sage Publications, Inc.

Paige, R. M. \& Stallman, E.M. (2007). Using instruments in education 
abroad outcomes assessment. In M.C. Bolen (Ed.). (2007). A guide to outcomes assessment in education abroad. Carlisle, PA: Forum on Education Abroad.

Pusch, M. D. (2004). Intercultural training in historical perspective. In D. Landis, J. M. Bennett, \& M.J. Bennett (Eds.). Handbook of Intercultural Training (3rd Ed., pp. 13-36). Thousand Oaks, CA: Sage Publications, Inc.

Rutherford, J. (1990). Identity: Community, Culture, Difference. London, UK: Lawrence \& Wishart Ltd.

Stewart, E. C. (1966). The simulation of cultural differences. Journal of Communication, 16(4), 291-304. doi:10.1111/j.14602466.1966.tb00043.x

Stewart, E. C. (1972). American cultural patterns: a cross-cultural perspective. Yarmouth, NE: Intercultural Press, Inc.

Stewart, E. C. (1986). The survival stage of intercultural communication. ICU Language Research Bulletin. 1(1), 109-121.

Stewart, E. C. (1987). The Japanese culture of organizational communication. In L. Taylor (Ed.). People, Communication, Organization. Vol. II. (pp. 136-182). Norwood, NJ: Aldex.

Stewart, E. C. (1995). Contrast culture training. In S. M. Fowler and M. G. Mumford (eds). Intercultural sourcebook: Cross-cultural training methods. Vol.1. (pp. 47-57). Yarmouth, ME: Intercultural Press.

Stewart, E. C., Danielian, J., \& Foster, R. (1969). Simulating intercultural communication through role-playing (Technical Report 69-7). Alexandria, VA: George Washington University.

Strauss, A. and Corbin, J. (1990). Basics of qualitative research: Grounded theory procedures and techniques. Newbury Park, CA: Sage.

Timmy-Toomy, S. (2004). Translating conflict face-negotiation theory into practice. In D. Landis, J.M. Bennett, \& M.J. Bennett (Eds.). Handbook of Intercultural Training ( $3^{\text {rd }}$ Ed., pp. 217-249). Thousand Oaks, CA: Sage Publications, Inc.

Tohoku University International Student Needs Assessment. (2008).

Retrieved from http://www.econ.tohoku.ac.jp/ KKS/

Torbiorn, I. (1994). Dynamics of cross-cultural adaptation. In Althen, G. (Ed.). Learning across cultures (pp. 31-55). Washington DC: NAFSA: Association of International Educators.

Verbik, L., \& Lasanowski, V. (2007). International student mobility:

Patterns and trends. World Education Services. Retrieved from www.wes.org/educators/pdf/StudentMobility.pdf

Wasilewski, J. H., \& Kawakami, H. S. (2012). Edward C. Stewart: Cultural dynamics pioneer. International Journal of Intercultural Relations, 36(6), 869-884. doi:10.1016/j.ijintrel.2012.08.012 
Ward, C. A., Bochner, S. \& Furnham, A. (2001). Psychology Culture Shock, $2^{\text {nd }}$ Ed. Philadelphia, PA: Routledge.

Ward, C. (2004). Psychological theory of culture contacts and their implications for intercultural training and interventions. In D. Landis, J.M. Bennett, \& M.J. Bennett (Eds.). Handbook of Intercultural Training ( $3^{\text {rd }}$ Ed., pp. 185-216). Thousand Oaks, CA: Sage.

HIROYOSHI HIRATSUKA is an assistant professor, School of Global Studies and Collaboration, Aoyama Gakuin University, Japan. His current research areas include managing organizational diversity and relational conflicts across cultures. Email: hhiratsuka@gsc.aoyama.ac.jp

HANAKO SUZUKI, PHD, is an assistant professor, Global Commons (International Student Center), University of Tsukuba, Japan. Her research areas include preventive intervention targeted at and identity of international students and scholars. Email: suzuki.hanako.fn@u.tsukuba.ac.jp

ALEXIS PUSINA, is Visiting Lecturer, Renmin University of China. His research interests include process based academic writing in TEFL, conflict resolution, and mediation in an intercultural communication context. 